\title{
Making physiotherapy more accessible: open access for general practitioners to a physiotherapy department
}

\author{
RUTH ELLMAN，SUE M ADAMS，J A REARDON，I H M CURWEN
}

\begin{abstract}
Open access to a physiotherapy outpatient department of a district general hospital was offered to general practitioners to whom domiciliary physiotherapy was already available. The effects of the new service have been monitored. Delays are reduced and consultants economise on time spent in merely confirming need for physiotherapy. Policies determining treatment, placing emphasis on prevention and self-help rather than prolonged treatment, are adhered to equally well by physiotherapists whether patients are referred directly or indirectly. It has proved unnecessary to restrict access to physiotherapy by insisting that general practitioners refer all patients first to consultant clinics. General practitioners have been sufficiently selective in referral and physiotherapists sufficiently economical in selecting treatment and determining its duration for the service to remain within the limits of available resources.
\end{abstract}

\section{Introduction}

In late 1978 general practitioners in one health district were invited to refer cases directly to the outpatient physiotherapy

Sutton and Wandsworth Health Authority, Merton, Surrey RUTH ELLMAN, MRCP, MFCM, senior registrar in community medicine

Queen Mary's Hospital, Roehampton, London SW15

SUE M ADAMS, MCSP, SRP, district physiotherapist

J A REARDON, MB, MRCP, senior registrar, department of rheumatology and rehabilitation (present appointment: consultant in rheumatology and rehabilitation, Croydon Area Health Authority, Croydon, Surrey)

I H M CURWEN, MB, DPHYSMED, consultant, department of rheumatology and rehabilitation department whereas formerly they had been obliged to refer them through a consultant. The service was available for a wide range of patients provided that they were able to reach the hospital without the help of an ambulance. This was in addition to a domiciliary physiotherapy service to which general practitioners already had open access.

The introductory letter to general practitioners explained that medical details should be given on the special proforma already in use for domiciliary physiotherapy. The physiotherapists would then make an initial assessment of what, if any, physiotherapy should be given. The general practitioner would be informed about treatment and remain clinically responsible. Hesitation before setting up such a service had been based on the fears discussed in the Tunbridge report ${ }^{1}$ that physiotherapists might be overwhelmed by requests, might be insufficiently selective, and might have difficulty in resisting demands for inappropriate or unduly prolonged courses of treatment.

To monitor the introduction of this service retrospectively required a review of its performance from several aspects. In this study medical records of the rheumatology and rehabilitation outpatient clinics and physiotherapist records have been studied and general practitioners questioned to provide an assessment of whether, without increase in physiotherapy staffing or reduction in standards, delays could be reduced and hospital medical staff relieved of the task of authorising all physiotherapy.

\section{Method}

Physiotherapy records were sampled systematically, taking one in four of all direct referrals over a 12-month period and a corresponding one-in-17 sample of referrals to the same outpatient physiotherapy department from hospital specialists other than those in paediatric and limb-fitting units. The sampling fractions were chosen to produce samples of similar size, 110 and 112 respectively. A one-in-four sample of domiciliary referrals, yielding 97 cases, was also examined. 
Details coded included age, sex, address, general practitioner, diagnosis as accepted by the physiotherapist, and delay from onset of symptoms to first physiotherapy session. The number of sessions and the period over which they were given was also recorded.

Records were examined of all patients newly referred to the rheumatology and rehabilitation outpatient clinic during January to March 1978, 1979, and 1980, to compare before, just after, and one year after introduction of the open-access scheme (table I). From these 537 cases information on diagnosis, on whether physiotherapy was arranged, and on delays was recorded.

TABLE I-Number of patients seen in rheumatology and rehabilitation outpatients clinic before, shortly after, and over a year after introduction of the direct-access service, showing numbers referred on for physiotherapy

\begin{tabular}{ccc}
\hline Period & New patients & Patients referred on for physiotherapy \\
\hline January-March 1978 & 172 & $129(75 \%)$ \\
January-March 1979 & 156 & $99(63 \%)$ \\
January-March 1980 & 209 & $94(45 \%)$ \\
& & \\
\hline
\end{tabular}

Nineteen general practitioners were asked to answer a short questionnaire over the telephone. These 19 had been selected to include one from every joint or multiple practice and one out of every two single-handed practices. The choice was not random but sought to be representative by including doctors who were known to be high, moderate, low, or non-users of the open-access service. They were asked for their criticisms, particularly regarding delays, choice, duration of courses of treatment, and feedback of information by physiotherapists. They were also asked about their selection criteria in terms of the broad categories suggested in the introductory letter as suitable for direct referral and, in greater detail, for one common complaint-that of low back pain.

\section{Results}

\section{USE MADE OF THE OPEN-ACCESS SERVICE}

The adult physiotherapy referral rate from the health district was seven a year per thousand population for direct referrals under the new scheme. In the same year 22 per thousand health district residents were referred to the outpatient physiotherapy department through consultants. Use of the open-access system by individual general practitioners varied from zero to 32 referrals a year, as estimated from the sample of cases examined. Those in partnerships used it more than single-handed doctors. Thus all those working in practices of three or more, half those with a single partner, but only one in five of those working single-handed used the service.

Analysis of physiotherapy records showed that $32 \%$ of the sample of patients referred directly to the physiotherapy outpatient department were over 60 compared with $24 \%$ of patients referred through consultants. Of patients referred for domiciliary physiotherapy, $88 \%$ were over 60 .

Table II indicates that direct referral as compared with consultant referral was particularly favoured for neck and shoulder pains. Cases of low back pain were, however, the most numerous in both

TABLE II-Numbers of patients referred by different routes with different types of problems

\begin{tabular}{|c|c|c|c|c|}
\hline \multirow{2}{*}{ Problem } & \multicolumn{2}{|c|}{$\begin{array}{c}\text { Through } \\
\text { open-access scheme }\end{array}$} & \multicolumn{2}{|c|}{$\begin{array}{l}\text { Through } \\
\text { consultant }\end{array}$} \\
\hline & $\begin{array}{c}\text { To } \\
\substack{\text { domiciliary } \\
\text { service }}\end{array}$ & $\begin{array}{c}\text { To } \\
\begin{array}{c}\text { physiotherapy } \\
\text { department }\end{array}\end{array}$ & $\begin{array}{c}\text { To } \\
\text { domiciliary } \\
\text { service }\end{array}$ & $\begin{array}{c}\text { To } \\
\text { physiotherapy } \\
\text { department }\end{array}$ \\
\hline \multicolumn{5}{|l|}{ Postoperative or fracture } \\
\hline Back pain & $\begin{array}{r}3 \\
11\end{array}$ & $\begin{array}{r}3 \\
43\end{array}$ & $\begin{array}{l}7 \\
0\end{array}$ & 27 \\
\hline Neck or shoulder pain & 2 & 41 & 1 & 19 \\
\hline Hip pain & 3 & 0 & i & 1 \\
\hline Other limb pain & 0 & 18 & 1 & 17 \\
\hline Respiratory disease & 31 & 1 & 8 & 9 \\
\hline Hemiplegia & 11 & 1 & 2 & 6 \\
\hline \multirow{2}{*}{$\begin{array}{l}\text { Generalised neurological or } \\
\text { muscular skeletal diseases } \\
\text { Other non-arthritic pain }\end{array}$} & & & & \\
\hline & $\begin{array}{l}9 \\
3\end{array}$ & $\begin{array}{l}0 \\
3\end{array}$ & $\begin{array}{l}7 \\
0\end{array}$ & $\begin{array}{l}3 \\
5\end{array}$ \\
\hline
\end{tabular}

samples. Hip and other joint pains were also commonly referred by either route. This pattern was in pronounced contrast to that of the domiciliary service, when respiratory disease and strokes predominated. Before outpatient open access became available general practitioners had sometimes requested domiciliary visits for mobile patients to avoid delay. Examination of records indicated that home visits were now made only to housebound patients.

\section{COURSES OF TREATMENT}

Courses of treatment were of similar duration whether patients were referred directly or indirectly (table III). They rarely exceeded three months; when they did, it was only after reconsultation with the general practitioner or with a consultant in the relevant discipline. Most courses were of fewer than five sessions. Single sessions were frequent: occasionally the physiotherapist considered treatment unnecessary but more often single sessions occurred because the physiotherapist thought one session of advice, reassurance, and exercise instruction sufficient.

TABLE III-Duration of courses of treatment given to patien:s referred by different routes

\begin{tabular}{lccc}
\hline \multicolumn{1}{c}{ Duration of course } & $\begin{array}{c}\text { GP, } \\
\text { domiciliary }\end{array}$ & $\begin{array}{c}\text { GP, } \\
\text { outpatient }\end{array}$ & $\begin{array}{c}\text { Consultant } \\
\text { (domiciliary } \\
\text { and outpatient) }\end{array}$ \\
\hline Three months or more & $11 \%$ & $6 \%$ & $9 \%$ \\
Five sessions or more but not extending & $19 \%$ & $39 \%$ & $37 \%$ \\
to three months & $49 \%$ & $32 \%$ & $28 \%$ \\
Two to four sessions & $17 \% \%$ & $20 \%$ & $15 \%$ \\
One session & $4 \%$ & $3 \%$ & $11 \%$ \\
\hline No session or not recorded & & & \\
\hline
\end{tabular}

\section{DELAYS}

Delays were indeed reduced. Whether referred directly or through a consultant those in whom need for immediate physiotherapy was evident from the referral note were seen without delay by a physiotherapist. Those with less urgent need were seen within five days on average if referred directly but had to wait an average of 24 days to see a clinician before being directed on for physiotherapy if referred through the rheumatologist. Referrals to the rheumatologist included many who were ineligible for the open-access physiotherapy scheme because they lived outside the district. The yearly number of outpatients seen by the rheumatologist was not reduced by the introduction of direct access, but the average time experienced by patients waiting for an outpatient appointment was substantially reduced from 50, before introduction, to 24 days. After the introduction of direct access the proportion of rheumatology patients referred on for physiotherapy fell from $75 \%$ in 1978 before direct access to $45 \%$ in 1980 (see table I). Physiotherapists, when concerned about diagnosis or progress, were able, with the general practitioner's agreement, to seek the rheumatologist's opinion. They did so in $4 \%$ of cases in 1980.

\section{OPINIONS OF GENERAL PRACTITIONERS}

General practitioners who used the service were well pleased with it and were in general agreement with the policy that courses of treatment should be determined by the physiotherapist and be brief. Only one thought courses were sometimes too brief. Criticisms were few and concerned delays and inadequate communication. Though all appreciated that delays for patients had been reduced, four commented that a year and a half after the service began patients with chronic complaints were having to wait slightly longer than had originally been necessary.

The reasons given by general practitioners for not using open-access physiotherapy were insufficient information about the new service (two doctors), disagreement with the principle that physiotherapists should assess whether and what treatment was indicated (3), or simply a belief that physiotherapy was a luxury inappropriate to NHS primary care (1).

General practitioners, when questioned by telephone, confirmed that users valued the open-access hospital service most highly for neck and back problems and the open-access domiciliary service 
most highly for respiratory conditions. They preferred to send new patients with rheumatoid arthritis or strokes initially to a consultant because of the diversity of potential treatment needs in such conditions. Most considered that soft-tissue injuries did not need physiotherapy, even though the introductory letter had suggested that they might be referred. Some general practitioners expressed themselves uncertain about which patients merited referral and welcomed more advice.

\section{REFERRALS FOR LOW BACK PAIN}

Specific questions on low back pain showed a diversity of opinion. Four doctors thought that early referral to a physiotherapist was valuable, and two others agreed that it was if the patient was in employment. Early referral did not imply that doctors expected such patients to receive physiotherapy throughout recovery. One emphasised that he expected that usually a single early session, providing advice on appropriate self-help, would be adequate. Most general practitioners delayed referral. Analysis of records showed that only $16 \%$ of patients whose symptoms had had an acute onset reached physiotherapy within a week of onset, and questioning found that seven of the doctors limited referral of patients with back pain to those with long-persistent symptoms. In discussion of criteria for back pain referral three doctors mentioned neurological signs and symptoms but, whereas one limited direct referral to such cases, two others, while using direct physiotherapy referral for uncomplicated cases, thought neurological signs necessitated referral to a consultant.

Communication from general practitioner to physiotherapist was of a high standard. In all cases the special proforma was correctly completed. Yet general practitioners received written reports in only $56 \%$ of outpatient cases. Comments from general practitioners indicated that most were nevertheless content, as additional information was obtained by telephone or relayed by the patients. Four of those questioned, however, were mildly dissatisfied at not receiving written notes on the proposed course of treatment after initial physiotherapy assessment.

\section{Discussion}

Attention has been drawn in recent years to the value of domiciliary physiotherapy, ${ }^{2-4}$ to which general practitioners have open access. Such services depend on the principle, supported by the DHSS, ${ }^{5}$ that physiotherapists should determine choice of treatment while doctors requesting physiotherapy should state diagnosis and treatment objective. Open access to the physiotherapy department is a further development dependent on this principle. Norman et $a l^{6}$ described a long-established open-access physiotherapy department and suggested that introduction of such services elsewhere would bring benefits. This study confirms that delays are reduced and that the consultant in rheumatology and rehabilitation can be given more time to advise on aspects other than physiotherapy.
It may be questioned whether reduced delay is itself valuable. The study showed that most general practitioners made allowance for natural recovery before referral. Those who did refer early did so for immediate advice and instruction in self-help. These general practitioners showed an understanding of the changing role of physiotherapy. The emphasis has moved away from prolonged courses of treatment to spending time teaching patients and relatives how to manage their own conditions.

In theory there is a need for physiotherapists to be protected from inappropriate demand from general practitioners but in practice this was not the case. In this department physiotherapists have the freedom to determine appropriate treatment. Continuing education is provided and frequent opportunities exist for discussion with colleagues and medical staff on management policies. With the support of senior therapy staff and of the consultant in rheumatology, physiotherapists have sufficient confidence to accept the additional demands and responsibilities placed on them in providing this service. In this district it proved possible to introduce the open-access scheme without demanding extra manpower resources and without diminishing the availability of physiotherapy for other categories of patients. The rationing imposed by general practitioners in their selection of patients and by physiotherapists in their control of the duration of courses of treatment proved a sufficient substitute for that imposed by the bottleneck of a consultant referral. It cannot be relied on to do so everywhere. Research into the outcome of physiotherapy, both physical and behavioural, is the only means by which rational decisions can be made on how much to spend on physiotherapy and how to select the most needy patients.

We gratefully acknowledge the help of general practitioners and all members of the physiotherapy department in the conduct of this study.

\section{References}

${ }^{1}$ Department of Health and Social Security. Rehabilitation. A report of the Standing Medical Advisory Committee. London: HMSO, 1972. (Tunbridge report.)

${ }^{2}$ Partridge CJ, Warren MD. Physiotherapy in the community Health Service Research Unit, University of Kent, 1977.

${ }^{3}$ Forster DP, First CEB, Francis BJ, Armstrong WD. A study of domiciliary physiotherapy in general practice. Community Medicine $1981 ; 3: 14-24$.

${ }^{4}$ Frazer FW. Domiciliary physiotherapy-cost and benefit. Physiotherapy $1980 ; 66: 1-7$.

${ }^{5}$ Department of Health and Social Security. Health service development: relationship between medical and remedial professions. (HC 77/33.) London: HMSO, 1977.

${ }^{6}$ Norman P, Clifton H, Williams E, Nichols PJR. Access by general practitioners to physiotherapy department of a district general hospital. Br Med F 1975 ;iv:220-1.

\section{Miniprint pages}

If you want to read in full size the articles that appear in miniprint in your edition of the $B M \mathcal{F}$ you may:

- Change your edition of the journal. If you want to read practice observed articles regularly you need the Practice Observed edition; if you want to read clinical research articles you need the Clinical Research edition.*

- Write to the publishing department for a full-sized copy of an individual article that appears in miniprint in your edition.
- Subscribe to a set of full-size pages to be sent at the end of each month. This service (subscription $£ 10$ a year) is designed mainly for readers who want to bind their journals.

- Arrange among your colleagues (in a group practice or hospital department, for example) for one person to subscribe to the alternative edition of the $B M \mathcal{F}$. Then everyone in the group will have access to both editions.

The editorial content of both editions is the same: the only difference is in the size of the print of the clinical research and practice observed sections. *This arrangement does not apply to permanently retired or associate members of the BMA, who receive the compact Clinical Research edition of the BMF
(which includes no advertisements). 